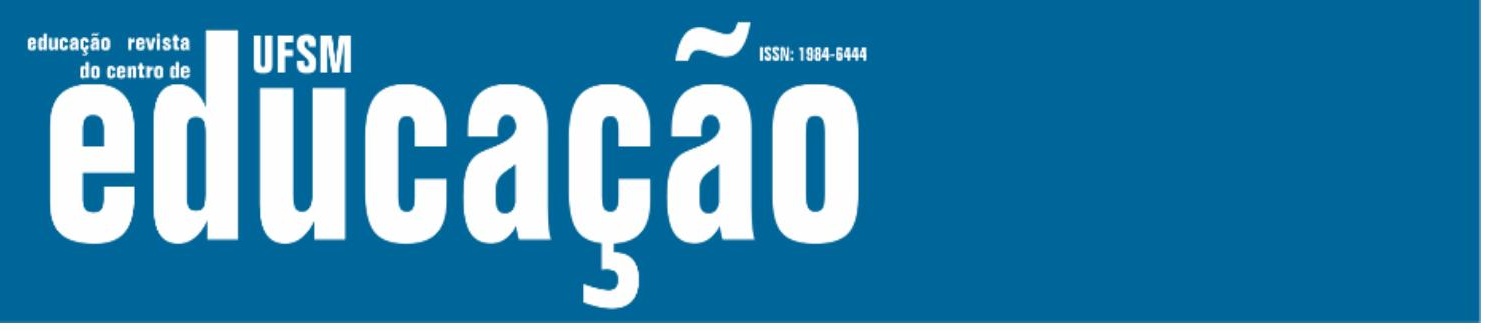

ISSN: 1984-6444 | http://dx.doi.org/10.5902/1984644443817

\title{
Neuroeducação e a construção de Indicadores de Habilidades Cognitivas
}

\section{Neuroeducation and the construction of Cognitive Skills Indicators}

\author{
Antonia Ediele de Freitas Coelho \\ Doutoranda do Programa de Pós-Graduação em Educação em Ciências e Matemáticas, Belém, Pará, \\ Brasil. \\ ediele.freitas@gmail.com - https://orcid.org/0000-0003-4715-4595 \\ João Manoel da Silva Malheiro \\ Professor Doutor Associado II na Universidade Federal do Pará, Castanhal, Pará, Brasil. \\ joaomalheiro@ufpa.br - https://orcid.org/0000-0002-2495-7806
}

Recebido em 08 de outubro de 2020

Aprovado em 05 de novembro de 2020

Publicado em 04 de novembro de 2021

\section{RESUMO}

Este estudo apresenta proposições de um instrumento de análise por meio dos pressupostos da Neuroeducação, evidenciando como Indicadores de Habilidades Cognitivas podem ser percebidos em falas e atitudes de alunos durante as aulas. Assume-se uma abordagem metodológica qualitativa, na qual se desenvolve uma revisão bibliográfica em artigos científicos, teses e livros publicados em periódicos da área da educação em ciências. Elaboram-se categorias denominadas de Bases Organizacionais das Habilidades Cognitivas, que resultam em alguns Indicadores de que essas Habilidades ocorrem em contextos reais e podem ser identificadas. Os resultados apontam que a Neuroeducação compreende um novo ramo de estudos, que propõe aproximar a educação em ciências de estudos relacionados a Neurociência e a Psicologia. Desse modo, esse instrumento possibilita análise de categorias que identifiquem Habilidades Cognitivas, compreendendo que o trabalho pedagógico promovido de maneira colaborativa e interativa auxilia na forma como o aluno adquire a manifesta aprendizagem.

Palavras-chave: Neuroeducação; Cognição; Indicadores de Habilidades Cognitivas.

\section{ABSTRACT}

This study presents proposals for an analysis instrument based on the assumptions of Neuroeducation, showing how Indicators of Cognitive Skills can be perceived in speeches and attitudes of students during classes. A qualitative methodological approach is taken, in which a bibliographic review is developed on scientific articles, theses and books published in journals in the area of science education. Categories called Cognitive Skills Organizational Bases are elaborated, which result in some 


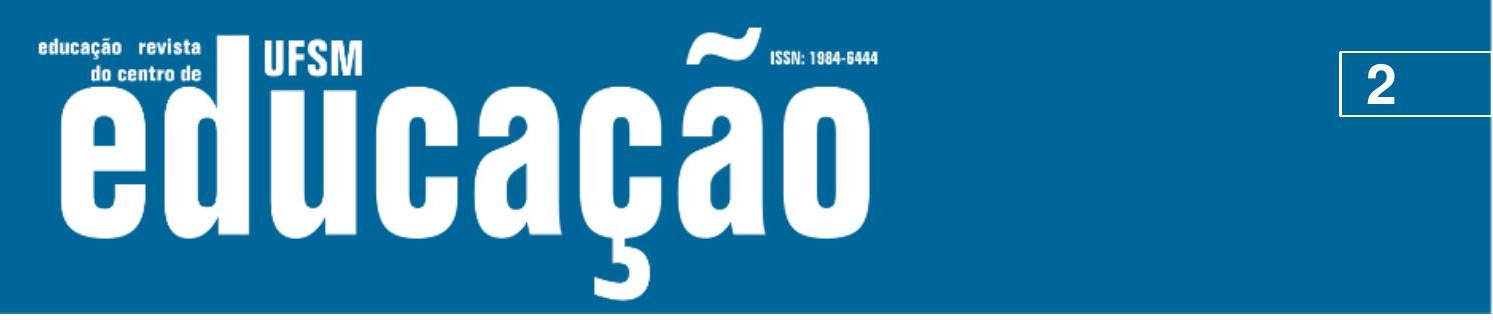

ISSN: 1984-6444 | http://dx.doi.org/10.5902/1984644443817

Indicators that these Skills occur in real contexts and can be identified. The results show that Neuroeducation comprises a new branch of studies, that proposes to bring science education closer to studies related to Neuroscience and Psychology. In this way, this instrument allows analysis of categories that identify Cognitive Skills, understanding that the pedagogical work promoted in a collaborative and interactive way helps in the way the student acquires the manifest learning.

Keywords: Neuroeducation; Cognition; Cognitive Skills Indicators.

\section{Introdução}

A popularização de ideias envolvendo questões sobre como o cérebro humano aprende e desenvolve conhecimento, tem se tornado um desafio para os educadores em sala de aula, pois são esses os mais comprometidos com esse processo. De acordo com Hardman et al. (2011), até que surjam formações específicas e aptas a preparar os professores a respeito dessas temáticas envolvendo a neurociência cognitiva, os docentes precisam pesquisar e se atualizar sobre os temas que envolvem o cérebro e o desenvolvimento cognitivo.

Dessa maneira, a Neuroeducação vem se consolidando como uma nova área do conhecimento que utiliza os saberes da Neurociência, da Psicologia e da Ciência da Educação como um caminho para que educadores e cientistas cognitivos tenham oportunidade de compreender como o ser humano desenvolve e manifesta sua aprendizagem em situações cotidianas que envolvem a sala de aula (TOKUHAMAESPINOSA, 2011).

Tokuhama-Espinosa (2008) acrescenta que a Neuroeducação recebe, ainda, outras nomenclaturas, mesmo que apresentem objetivos comuns: educação cerebral, neuropsicologia cognitiva e neurociência cognitiva. Assim, concorda-se com a autora, ao considerar que o termo Neuroeducação é definido e utilizado em vários estudos, quando a investigação científica se propõe a utilizar as pesquisas empíricas realizadas, como forma de ajuizar melhores práticas pedagógicas, e, esse compreende um dos objetivos dessa investigação.

As investigações que são realizadas considerando a Neuroeducação, analisam duas vertentes, segundo Oliveira (2015): a primeira, voltada para o estudo de 


\section{تilloapão \\ 3}

ISSN: 1984-6444 | http://dx.doi.org/10.5902/1984644443817

Figura 2 - Níveis de conhecimento

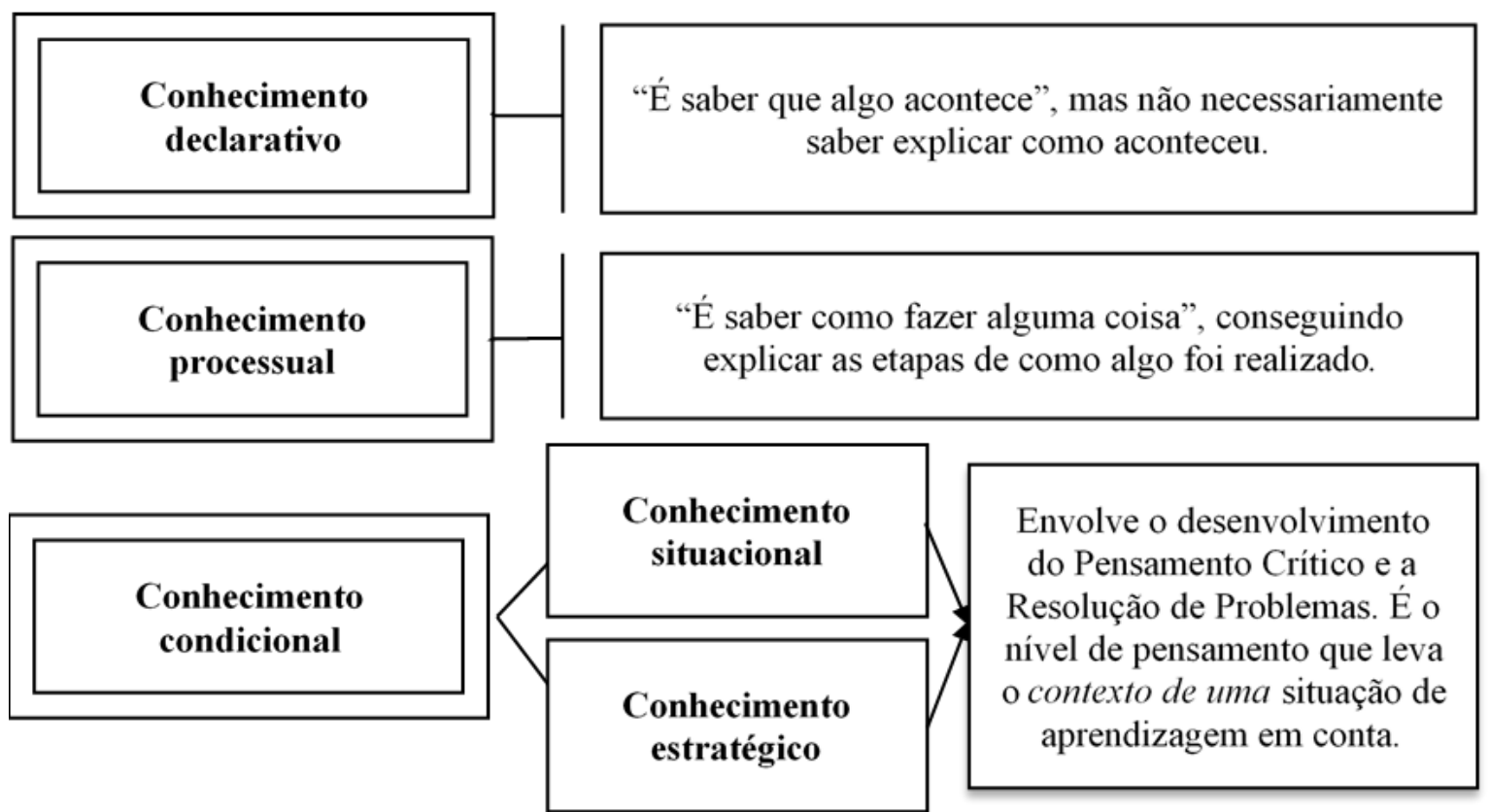

Fonte: Elaborado a partir de Zoller e Pushkin (2007) adaptação de Coelho (2016)

Desse modo, o conhecimento apresenta algumas características que podem ser identificadas e direcionadas em conformidade com os níveis definidos por Zoller e Pushkin (2007). Apesar disso, essas etapas não seguem um padrão fixo em seu desenvolvimento, podendo ser identificados de forma eventual, dependendo dos estímulos que são recebidos pelos estudantes.

Sobre isso, Sternberg (2010) acrescenta que o ato de refletir deve ser considerado como um processo inerente ao conhecimento. Para esse autor "o conhecimento sem reflexão é inútil, e a reflexão sem conhecimento é vazia" (p. 7), significa dizer que, é preciso que exista uma correspondência na relação existente entre a aprendizagem de conceitos e a reflexão que se constitui durante esse processo.

Desse modo, segundo Sternberg (2010), é necessário destacar que a capacidade de aprendizagem, de elaborar conhecimentos, não é algo definido exclusivamente pela genética ou então unicamente determinado pelo ambiente, pois aprender está condicionado tanto pelas relações com o meio ambiente, quanto pela criação familiar. 


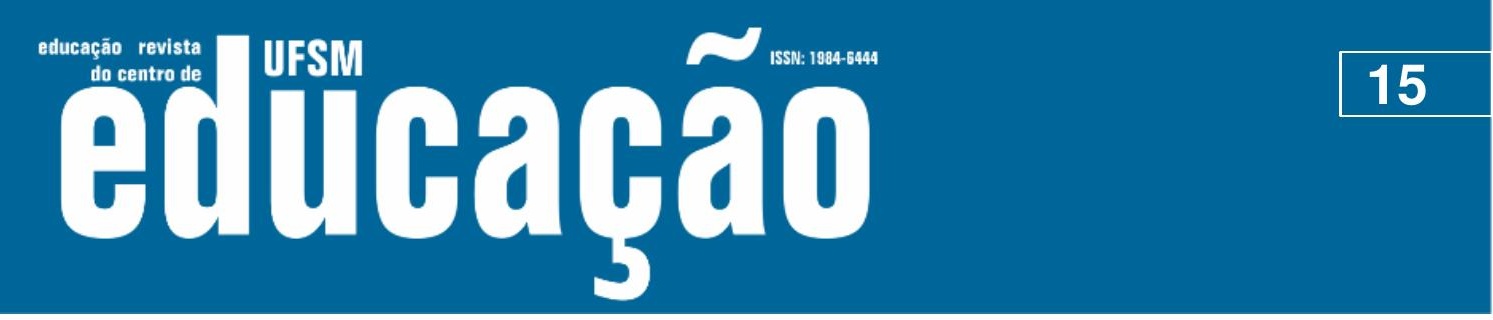

ISSN: 1984-6444 | http://dx.doi.org/10.5902/1984644443817

\section{As Habilidades Cognitivas}

Em suas pesquisas, Oliveira (2015) evidencia que na atualidade, nenhum educador sério e comprometido com a aprendizagem de seus educandos, deixa de considerar a relevância tanto da herança biológica (fenótipo) quanto da herança sóciohistórico-cultural (meio ambiente) na manifestação de características físicas e comportamentais nos seres humanos, entre elas a inteligência, de seus alunos. Por conta disso, o autor ressalta que considera indispensável ao educador o estudo sobre as bases neurais da aprendizagem.

Para Oliveira (2015, p. 51), "após o nascimento, com a história de vida de cada um, é que se construirá o cérebro de cada um, desfazendo e reorganizando constantemente as interligações sinápticas entre os bilhões de neurônios". Assim, ao longo dos anos, o desenvolvimento e a sobrevivência da espécie humana, vêm sendo atrelada à educação. Sendo assim, é necessário à prática pedagógica reconhecer a participação de fatores ora genéticos, ora ambientais e, ora a combinação desses fatores como determinantes para a constituição do indivíduo, do ponto de vista físico e comportamental.

Acrescenta-se que, educar é facilitar a aquisição de novos comportamentos, novas habilidades, que resultam do funcionamento do cérebro, órgão do pensamento, de acordo com Thompson (2011). Considerando isso, atuar pedagogicamente compreende saber lidar com as diferenças que envolvem os sujeitos, implica em um processo dialético de mediação entre o sujeito que aprende e o objeto do conhecimento.

Thompson (2011), com base em Levine (2003), elenca 10 áreas que devem ser levadas em consideração ao analisar estímulos que permitam à criança estabelecer associações significativas em suas aprendizagens. Desse modo, consideramos e ressaltamos as habilidades que podem ser evidenciadas, a partir das categorias elencadas por Levine (2003):

1) Controle de atenção ou capacidade de concentração de recursos mentais: refere-se à habilidade de concentração para a realização de determinadas atividades, podendo permitir ao indivíduo maior dedicação e atenção ao que 


\section{تilloapẫ}

ISSN: 1984-6444 | http://dx.doi.org/10.5902/1984644443817

está sendo desenvolvido;

2) Controle de recepção ou capacidade de retardar a recompensa e se tornar processador ativo da informação: com essa habilidade, o sujeito se permite monitorar cada etapa de desenvolvimento de atividade, em busca de solucionar determinado problema;

3) Controle de expressão ou capacidade de pensar sobre as alternativas: com esta aptidão, o indivíduo se torna capaz de analisar, averiguar, ponderar e verificar cada hipótese levantada com mais precisão;

4) Ordenação sequencial ou capacidade de agir passo a passo: com o desenvolvimento e manifestação desta habilidade, almeja-se que o indivíduo consiga organizar suas ideias de maneira ordenada, de forma que cada etapa de desenvolvimento de suas aptidões ocorra em uma sequência lógica;

5) Orientação espacial ou capacidade de se engajar ao pensamento verbal produtivo: compreende a habilidade de organizar e verbalizar as ideias como forma de auxiliar no desenvolvimento de atividades;

6) Memória ou capacidade de usar seus arquivos de forma consciente: referese à eficácia de utilizar os dados ou fatos memorizados de maneira a desenvolver novas aprendizagens;

7) Linguagem ou capacidade de se tornar comunicador verbal: abrange a habilidade de comunicação, de utilização da linguagem como forma de comunicação e, consequentemente, de orientação para o desenvolvimento da aprendizagem;

8) Motricidade ou capacidade de um nível satisfatório de eficiência motora: habilidade em desenvolver técnicas de eficiência motora que são essenciais para a aprendizagem, como a coordenação motora, por exemplo;

9) Pensamento social ou capacidade de compreender as habilidades interpessoais: envolve a habilidade de empatia, convívio com o outro, em que as opiniões alheias são passíveis de serem ouvidas e consideradas;

10) Pensamento superior ou capacidade de se tornar analista conceitual, criativo, sistêmico e crítico: como o próprio nome especifica, compreende a habilidade de assimilar às informações adquiridas em outras instâncias, para 


\section{FEM olluarao

ISSN: 1984-6444 | http://dx.doi.org/10.5902/1984644443817

O N5 se diferencia dos demais, sobretudo, por evidenciar o momento em que o aluno desenvolve a habilidade de abordar ou generalizar o problema em outros contextos ou condições iniciais, que não se resumem ao que está sendo discutido, isto é, demonstra capacidade de associar os conhecimentos científicos estudados aos seus conhecimentos do cotidiano, percebendo que a ciência pode ser evidenciada em diferentes contextos, sem perder seus significados conceituais, para além disso, atribuem-se valores aos saberes do dia a dia, aproximando-os da sala de aula.

Com o N5, o aluno provavelmente já perpassou pelos níveis anteriores, evidenciando hipóteses, sugerindo soluções, dando opiniões e modificando-as, quando considerasse necessário, por isso, este é o momento marcado pela descoberta de uma teoria ou conceito já antes formulado, mas que agora pertence a um lugar que não aquele presente unicamente nas teorias discutidas; é um saber prático que o próprio aluno constrói junto dos pares, com auxílio de alguém mais experiente.

Assim, percebe-se que os Indicadores de Habilidades Cognitivas são atingíveis, contanto que sejam capazes de abranger um conjunto de acontecimentos que consideram o aluno como o centro do processo, consentindo assim, mudanças na ideia de conceituação, na qual a investigação, o conhecimento e a educação precisam estar em conformidade com a inovação, a contextualização, a interdisciplinaridade e a avaliação de procedimentos e técnicas para a investigação de diversificadas metodologias para o ensino de ciências (ZOLLER, 2011).

Considera-se relevante destacar que, 0 que distingue as Habilidades Cognitivas de alta ordem das de baixa ordem, é a maneira como os alunos enfrentam/solucionam os problemas ou situações até então desconhecidas, sendo essas não-algorítmicas ou compostas de perguntas abertas, envolvendo contextos que não se resumem a situações familiares ou habituais (ZOLLER; PUSHKIN, 2007).

Além disso, Fonseca (2018, p. 316-317) elenca uma sequência de operações e estágios mentais que compreendem o que o autor chama de tríade de funções e subfunções cognitivas, podendo ser assim representadas:

- Funções de input, de recepção ou de captação: compreende a atenção sustentada, percepção analítica; sistematização na exploração dos dados; 


\section{FFM Eltothato

ISSN: 1984-6444 | http://dx.doi.org/10.5902/1984644443817

discriminação e ampliação de instrumentos verbais, orientação espacial com sistema de referência automatizados; conservação e agilização de constâncias (tamanho, forma, quantidade, profundidade, movimento, cor, orientação, dados intrínsecos e extrínsecos, etc.); precisão e perfeição na apreensão de dados; filtragem, fixação, focagem e flexibilização sustentadas em fontes de informação simultânea, etc.;

- Funções de integração, retenção e de planificação: refere-se a definição detalhada de situações-problema; seleção de dados relevantes; minimização e eliminação de dados irrelevantes; comparação, classificação e conferência de propriedades comuns e incomuns de dados; estabelecimento de comparações, ligações, semelhanças, dissemelhanças, analogias; memorização, manipulação e recuperação da informação; ampliação do campo mental em jogo, integração sistemática da realidade; estabelecimento de relações e sistemas de relações; supervisão das situações e problemas; desenho de estratégias para testagem de hipóteses; utilização do pensamento indutivo; dentre outros;

- Funções de output, de execução ou de expressão: compreende a comunicação clara e evidente, compreensível, desbloqueada e contextualizada; projeção de relações virtuais; transposição psicomotora (transporte ideatório, ideomotor e visóriográfico); expressão verbal fluente e melódica; regulação, iniciação, verificação, conclusão e precisão de respostas adaptativas; enriquecimento de instrumentos não verbais e verbais de expressão; avaliação e retroação das soluções criadas, etc.

Em relação a isso, compreende-se que muito embora a cognição não possa reduzir-se a um modelo de processamento de informação, podemos considerar que a cognição humana e a capacidade de aprendizagem "envolvem a integração dinâmica, coerente e sistêmica das três ferramentas cognitivas principais anteriormente referidas" (FONSECA, 2018, p. 325).

Logo, para que o aluno aprenda a aprender é necessário que se pratique, treine, aperfeiçoe e redesenvolva essas funções ou habilidades cognitivas, abrangendo as capacidades conativas e executivas, que costumam ser pouco estimuladas, tanto na escola, quanto fora dela. 


\section{त Hsm

ISSN: 1984-6444 | http://dx.doi.org/10.5902/1984644443817

\section{Os Indicadores de Habilidades Cognitivas: competências necessárias para a manifestação da aprendizagem}

Percebe-se que a Neuroeducação nos dá vários indícios de como as informações são acessadas, selecionadas e organizadas pelo cérebro humano até formar o que concebemos por aprendizagem. Essas informações serviram de base para que pudéssemos compreender de que modo o ensino pode ser estruturado, para que seja possível identificar os Indicadores de Habilidades Cognitivas em crianças que estão em fase escolar.

Considera-se relevante destacar que, embora existam diversificados níveis, classificações ou pontos de vistas distintos sobre como a aprendizagem se manifesta nos sujeitos, os tópicos destacados aqui se estruturam por meio das convergências encontradas entre as discussões levantadas. Por conta disso, estruturamos três categorias que englobam conjuntos de habilidades que devem ser manifestadas conforme as atividades se desenvolvem ao longo das aulas.

Nomeia-se essas categorias de Bases Organizacionais de Habilidades Cognitivas, e a partir delas definimos alguns Indicadores de Habilidades Cognitivas que procuram evidenciar de que maneira os professores podem perceber em seus alunos o desenvolvimento e a manifestação de tais habilidades, considerando as características principais de seus indícios, que envolvem a forma como os estudantes demonstram que estão compreendendo as informações discutidas, sobretudo, por meio da fala, e como isso pode ser caracterizado como aprendizagem.

Ressalta-se, ainda, que essas três Bases Organizacionais são capazes de fornecer elementos suficientes e necessários de serem considerados, na ocasião de preparação e planejamento de aulas, nas quais se almejem o desenvolvimento e a manifestação de Indicadores de Habilidades Cognitivas.

A primeira dessas três Bases Organizacionais se refere à Habilidade Cognitiva de Assimilação Básica, que como o próprio nome expressa, refere-se a capacidade de exposição dos pensamentos por meio da recordação básica de informações conhecidas, incluindo a aptidão para monitorar as etapas de desenvolvimento das atividades, almejando a resolução de determinado problema, mesmo que o contexto 


\section{Tusm

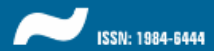

ISSN: 1984-6444 | http://dx.doi.org/10.5902/1984644443817

associação do conceito científico estudado com o cotidiano, citando exemplos plausíveis e justificados por meio de explicações congruentes ao que está sendo realizado, ou seja, as atividades investigativas realizadas são associadas aos conhecimentos prévios dos alunos, podendo ser percebido por meio de comparações com lendas, acontecimentos, histórias, etc.

Definidas e esclarecidas cada uma das Bases Organizacionais e dos Indicadores de Habilidades Cognitivas, a figura 3 procura exemplificá-los em sua distribuição, de acordo com suas características:

Figura 3 - Bases Organizacionais de Habilidades Cognitivas

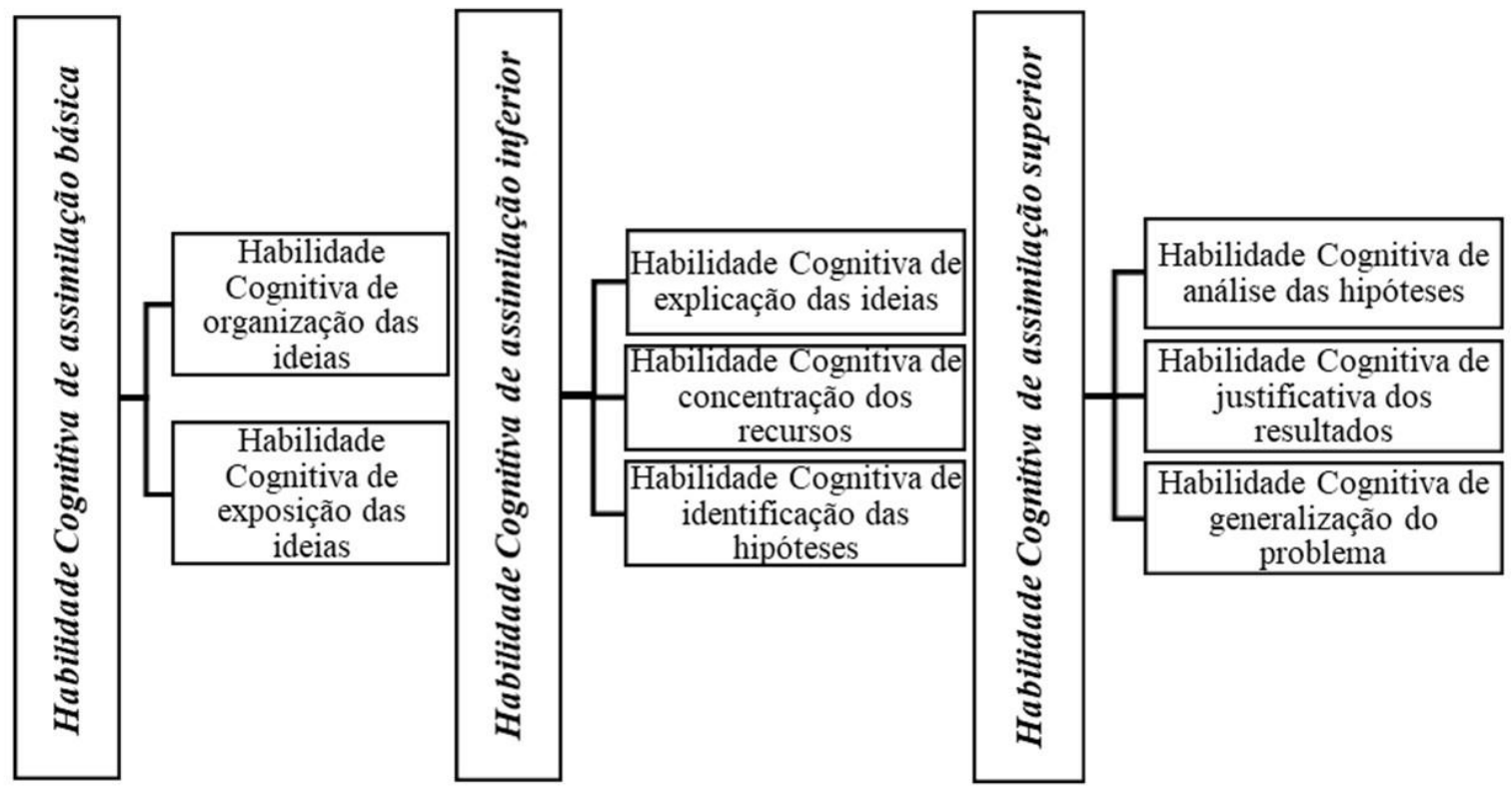

Fonte: Elaborado pelos autores com base nos dados da pesquisa (2020)

Essas definições e divisões dos indicadores dentro das Bases Organizacionais foram selecionadas segundo as qualificações percebidas em cada um deles, com o intuito de melhor exemplificar seus objetivos. Apesar dessa organização em categorias, os indicadores não seguem uma ordem sistêmica de manifestação, ou seja, podem emergir em diferentes ocasiões, em conformidade com os objetivos das atividades que estão sendo desenvolvidas. 


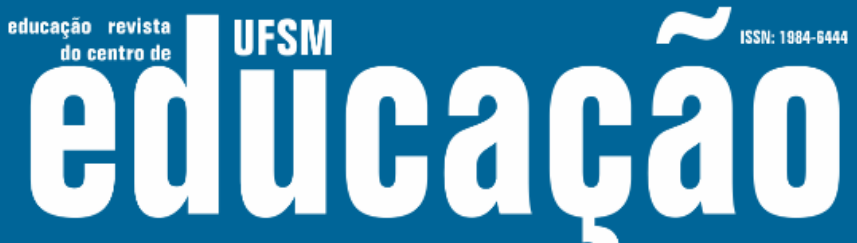

ISSN: 1984-6444 | http://dx.doi.org/10.5902/1984644443817

\section{Considerações finais}

Essa pesquisa almejou apresentar proposições de uma ferramenta de análise por meio dos pressupostos da Neuroeducação, que serviram como suporte para definir os Indicadores de Habilidades Cognitivas, que podem ser percebidos em falas e atitudes de alunos. Dessa forma, traçou-se um caminho no qual se identificou o pensamento, o conhecimento e a memória, além da cognição, até chegar as Bases Organizacionais das Habilidades Cognitivas e, por fim, aos Indicadores de Habilidades Cognitivas.

Com base nisso, percebe-se que os Indicadores de Habilidades Cognitivas compreendem uma possibilidade de análise de como o aluno pode (ou não) estar desenvolvendo e manifestando a aprendizagem, tendo a possibilidade de auxiliar os professores a analisarem suas práticas em sala de aula, podendo verificar como seus procedimentos metodológicos estão sendo percebidos pelos estudantes.

Essa possibilidade de ferramenta de análise, surge como uma alternativa para a realização de pesquisas que consideram não somente a fala, mas também as atitudes dos alunos diante dos desafios que lhes são impostos durante as aulas. Além disso, estimular que os estudantes possam expor seus pensamentos, suas ideias, é ainda uma forma de identificar "se" e "como" a aprendizagem está ocorrendo.

A proposta aqui apresentada, deve ser considerada flexível e adaptável para quem se interessar por utilizá-la como ferramenta de análise. Almeja-se potencializar os aspectos que podem ser observados por meio de falas e atitudes, e que podem justificar se as Habilidades Cognitivas são possíveis de serem identificadas. Acreditase que diversificadas propostas metodológicas podem ser analisadas dentro da perspectiva apresentada e, que a atuação do professor poderá ser decisiva para que os indícios de aprendizagem surjam.

Finaliza-se ressaltando que, ao refletir e questionar sobre a possibilidade de desenvolvimento cognitivo dos seus alunos, com base na análise de sua própria prática, pode ser um caminho para que os professores se sintam aptos a replicar suas ideias consolidadas, ou ainda, criar possibilidades de ensino, dependendo dos resultados que obtiverem ao Identificar as Habilidades Cognitivas que mais se 


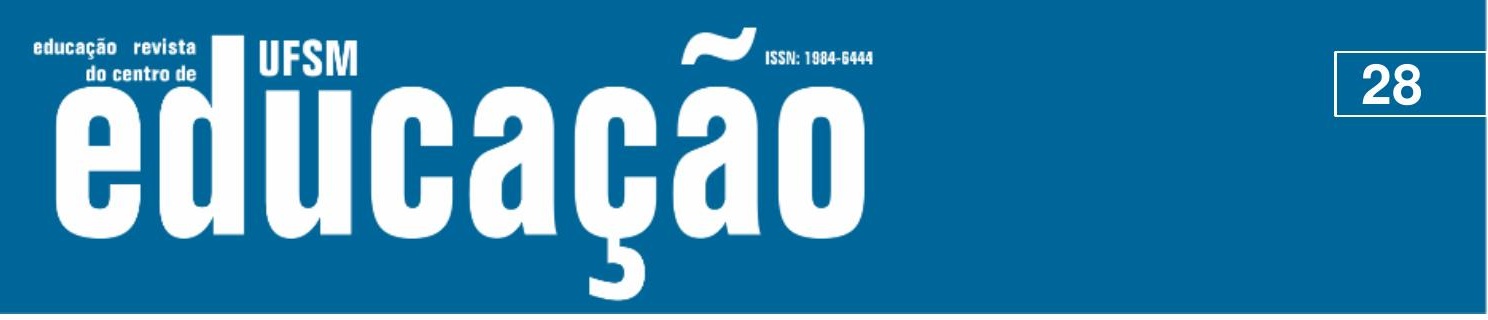

ISSN: 1984-6444 | http://dx.doi.org/10.5902/1984644443817

destacam em seus alunos.

\section{Referências}

BOGDAN, Robert; BIKLEN, Sari. Investigação qualitativa em educação. Porto: Porto Editora, 1994.

COELHO, Antonia Ediele de Freitas. Desenvolvimento de Habilidades Cognitivas em um curso de férias: a construção do conhecimento científico de acordo com a Aprendizagem Baseada em Problemas. (Dissertação) Mestrado em Educação em Ciências e Matemáticas. Belém (PA). Universidade Federal do Pará (UFPA). 101f, 2016.

DINIS, Carlos Manoel Santos Jacinto. O que é a Filosofia para crianças: Programa de Matthew Lipman. 96f. Dissertação (Mestrado em Filosofia-ética e política) Universidade da Beira Interior. Covilhã, 2011.

FONSECA, Vitor da. Papel das funções cognitivas, conativas e executivas na aprendizagem: uma abordagem neuropsicopedagógica. In: Guia prática de Neuroeducação: neuropsicopedagogia, neuropsicologia e neurociência. PEDRE, W. (org). 2ed. Rio de Janeiro: Wak editora, 2018.

GIL, Antonio Carlos. Como elaborar projetos de pesquisa. 4. ed. - São Paulo: Atlas, 2002.

GUERRA, Leonor Bezerra; CONSENZA, Ramon Moreira. Neurociência e educação: como o cérebro humano aprende. 1ed. Porto Alegre: Artmed, 2011.

HARDMAN, Mariale et al. Neuroeducation: Learning, Arts, and the Brain. New York: Dana Press, 2011.

HELENE, André Frazão; XAVIER, Gilberto Fernando. A construção da atenção a partir da memória. Rev Bras Psiquiatr, v. 25, n. 2, p.12-20, 2003.

LEVINE, Mel. Educação individualizada. Rio de Janeiro: Campus, 2003.

LIPMAN, Matthew. A Filosofia vai à Escola. São Paulo: Summus Editorial, 2010.

LIPMAN, Matthew. O pensar na educação. Petrópolis: Vozes, 1995.

MINAYO, Maria Cecília Souza. O desafio do conhecimento. 11. ed. - São Paulo: Hucitec, 2008. 


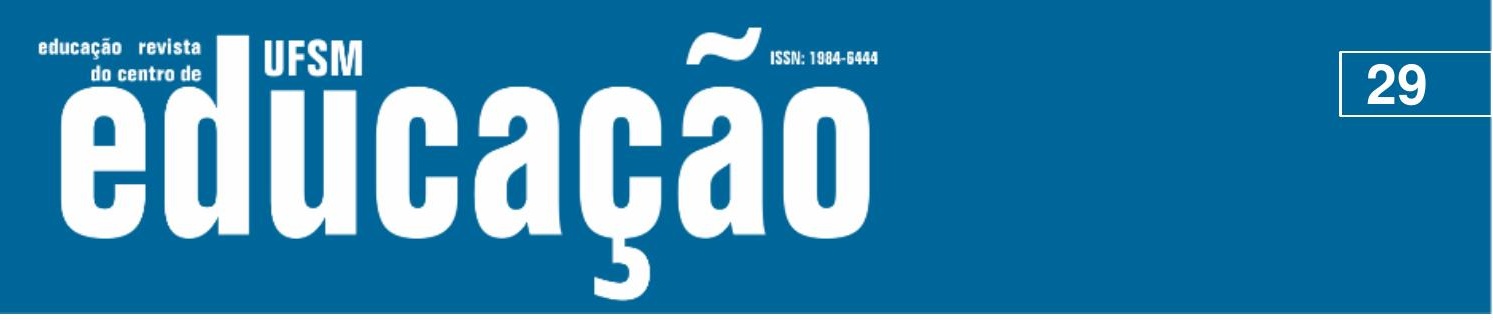

ISSN: 1984-6444 | http://dx.doi.org/10.5902/1984644443817

MIRI, Barak; DAVID, Bem-Chaim.; ZOLLER, Uri. Purposely Teaching for the Promotion of Higher-order Thinking Skills: A Case of Critical Thinking. Science Education. v. 2, n. 27, p. 353-369, 2007.

OLIVEIRA, Gilberto Gonçalves. A pedagogia da neurociência: ensinando o cérebro e a mente. 1ed. Curitiba: Appris, 2015.

SASSERON, Lúcia Helena. Alfabetização Científica no Ensino Fundamental: Estrutura e Indicadores deste processo em sala de aula. (Tese) Doutorado em Educação. São Paulo (SP) Universidade de São Paulo (Usp). 265f, 2008.

SENA, Tania Virgínea. Neuroeducação: conceitos, estratégias e técnicas para a sala de aula do futuro. 1ed. Salvador: ebook kindle, 2015.

SOUSA, Aline Batista de; SALGADO, Tania Denise Miskinis. Memória, aprendizagem, emoções e inteligência. Revista Liberato, Novo Hamburgo, v. 16, n. 26, p. 101-120, 2015.

STERNBERG, Robert. Psicologia Cognitiva. 5. ed. São Paulo, SP: CENGAGE Learning, 2010.

TEIXEIRA, João Fernandes. Mente, cérebro \& cognição. 4. ed. Petrópolis, RJ: Ed. Vozes, 2000.

THOMPSON, Rita. Neuroeducação: um novo olhar sobre a relação entre saúde e educação. In: Neuroeducação: a relação entre saúde e educação. MAIA, H. (org.) Rio de Janeiro: Wak Editora, 2011.

TOKUHAMA-ESPINOSA, Tracey Noel. The scientifically substantiated art of teaching: a study in the development of standards in the new academic field of neuroeducation (Mind, Brain, and Education Science). 625f. Tese de doutorado (Doutorado em filosofia). Capella University, 2008.

TOKUHAMA-ESPINOSA, Tracey Noel. Why mind, brain, and education science is the "new" brain-based education. Article published in New Horizons in Education. Jan, 2011.

ZOLLER, Uri; PUSHKIN, David. Matching Higher-Order Cognitive Skills (HOCS) promotion goals with problem-based laboratory practice in a freshman organic chemistry course. Chemistry Education Research and Practice, v. 8, n. 2, p. 153171, 2007.

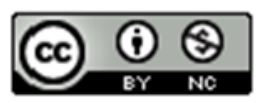

This work is licensed under a Creative Commons Attribution-NonCommercial 4.0 International (CC BY-NC 4.0) 